\title{
General thoracic surgery is safe in patients taking clopidogrel (Plavix)
}

\author{
Robert James Cerfolio, MD, FACS, FCCP, ${ }^{\text {a }}$ Douglas J. Minnich, MD, ${ }^{\mathrm{b}}$ and \\ Ayesha S. Bryant, MSPH, MD
}

Background: The objective of this study was to assess the safety of general thoracic surgery in patients taking antiplatelet (clopidogrel) therapy.

\begin{abstract}
Methods: A prospective study was conducted of consecutive patients who underwent general thoracic surgery and who were taking clopidogrel perioperatively. They were matched using a propensity score from our prospective database of 11,768 patients. Intraoperative and postoperative outcomes were compared.
\end{abstract}

Results: Between January 2009 and April 2010 there were 33 patients on clopidogrel at the time of surgery and 132 controls. The most common procedures were thoracotomy with lobectomy in 11 patients (robotic in 1), video-assisted wedge resection in 6, mediastinoscopy in 4, and Ivor Lewis esophagogastrectomy in 2 . Epidurals were not used. There was no intraoperative morbidity or bleeding in primary thoracotomy; however, 2 of the 4 patients who underwent redo thoracotomy had bleeding that required transfusions. None of the 8 patients receiving clopidogrel who had a coronary artery stent and underwent lobectomy had a perioperative myocardial infarction whereas 5 of the 14 control patients undergoing lobectomy who had a coronary artery stent $\operatorname{did}(P=.05)$. Otherwise, morbidity, mortality, and length of stay were no different.

Conclusions: Patients who are receiving clopidogrel and who have a coronary artery stent placed can safely undergo general thoracic surgery. The widely held belief that surgery cannot be performed without bleeding is untrue. This new finding not only eliminates much of the preoperative dilemma posed by these patients but also may reduce their risk of a postoperative myocardial infarction. However, patients who require a redo thoracotomy may be at increased risk of bleeding. (J Thorac Cardiovasc Surg 2010;140:970-6)

Earn CME credits at

http://cme.ctsnetjournals.org

Given the increased risk of coronary thrombosis, the standard of care after the percutaneous insertion of metal and/ or drug-eluting stents is to place a patient on a regimen of thienopyridines (eg, clopidogrel [Plavix], Sanofi-Aventis, Bridgewater, NJ; ticlopidine [Ticlid], Hoffmann-LaRoche, Nutley, NJ) and aspirin. Owing to the risk of neutropenia

From the Division of Cardiothoracic Surgery, Section of Thoracic Surgery, ${ }^{\mathrm{a}}$ and Division of Cardiothoracic Surgery, Department of Surgery, ${ }^{b}$ University of Alabama at Birmingham, Birmingham, Ala.

Disclosures: Robert J. Cerfolio: E plus health care, speaker; Ethicon, speaker/consultant; Neomend, consultant; Millicore, speaker/consultant; Medela, speaker/consultant; Closure/J\&J, consultant; OSI Pharm, speaker; Atrium, consultant/speaker; Oncotech, speaker; Covidien, speaker; Precision, consultant/speaker. Douglas J. Minnich and Ayesha S. Bryant have no financial disclosures to report.

Read at the 90th Annual Meeting of The American Association for Thoracic Surgery, Toronto, Ontario, Canada, May 1-5, 2010.

Received for publication May 3, 2010; revisions received July 12, 2010; accepted for publication July 19, 2010; available ahead of print Sept 1, 2010.

Address for reprints: Robert J. Cerfolio, MD, Professor of Surgery, Chief of Thoracic Surgery, Division of Cardiothoracic Surgery, University of Alabama at Birmingham, 703 19th St S, ZRB 739, Birmingham, AL 35294 (E-mail: Robert. cerfolio@ccc.uab.edu).

0022-5223/\$36.00

Copyright (C) 2010 by The American Association for Thoracic Surgery doi:10.1016/j.jtcvs.2010.07.051 with ticlopidine, most cardiologists have used clopidogrel (Plavix; Bristol-Myers Squibb/Sanofi-Aventis, New York, NY), which selectively inhibits the binding of adenosine diphosphate to its platelet receptor and the subsequent adenosine diphosphate-mediated activation of the glycoprotein IIb-IIIa complex. This inhibits platelet aggregation. ${ }^{1}$ It reaches its peak activity after 3 to 5 days and produces a prolonged antiplatelet effect of 7 to 10 days. Several reports have shown the dramatically increased risk of coronary thrombosis of up to $29 \%$ if clopidogrel is withdrawn prematurely. ${ }^{2}$ In fact, a sudden withdrawal of clopidogrel has been shown to have a rebound effect with an increase in the hypercoagulation and prothrombotic state. ${ }^{2-5}$ The recent recommendation from the American Heart Association's Science Advisory Committee is that patients who have undergone placement of a drug-eluting coronary artery stent should continue to receive dual antiplatelet therapy for at least 12 months. ${ }^{6,7}$ These landmark recommendations have changed the landscape of the preoperative management of these patients all over the world. Many institutions held emergency meetings between the heads of cardiology, anesthesiology, and surgery to promulgate policy for these patients. The result was a swirling morass of anxiety and confusion. These rules mandated that no patients have their clopidogrel stopped for 6 months if they had a sirolimus stent placed in their coronary arteries, for 3 months if they had a paclitaxel stent, or for 1 month if they had a bare metal stent. ${ }^{8}$ Thus, patients with known malignant disease 


\section{Abbreviation and Acronym}

IRB $=$ institutional review board

who had poor results from a preoperative stress test and required a coronary stent often received a bare metal stent, followed by 1 month of clopidogrel and then surgery 1 or 2 weeks later to minimize the risk of bleeding. This therapy compromised their coronary artery disease treatment with perhaps a nonoptimal stent and simultaneously delayed their cancer surgery for at least 6 weeks. In addition, it exposed them to higher risk of a perioperative myocardial infarction. Because of this complicated, volatile, and politically charged situation, we decided to assess the safety of a less volatile and simpler solution by operating on patients who were taking clopidogrel and observing outcomes. In this study, we report our initial results.

\section{METHODS}

This is a prospective study of a consecutive series of patients who received clopidogrel up to and including the day of thoracic surgery as well as each day postoperatively. These patients were matched 1:4 with patients who were not receiving clopidogrel at the time of surgery using a propensity score (greedy matching technique). All patients were 19 years of age or older. Thirty-day major adverse cardiac events were recorded. A major adverse cardiac event is defined as nonfatal myocardial infarction and/or cardiac death as previously defined by the American College of Cardiology/ European Society of Cardiology. ${ }^{9}$ This study was approved by the University of Alabama at Birmingham Institutional Review Board (IRB). Individual consent for inclusion in the study was waived, but consent for inclusion for our prospective database was obtained.

Any patient who was smoking cigarettes 2 weeks before the operation was classified as a current smoker. The patient was defined as receiving preoperative chemotherapy only if it was related to lung cancer.

To reduce the influence of selection on the comparison of outcome, we used propensity scores to match patients who were receiving clopidogrel at the time of pulmonary resection to those that were not receiving clopidogrel during pulmonary resection. ${ }^{10}$ The propensity-matched analysis is a balancing score method that attempts to correct bias in patient selection by creating equivalent risk groups for analysis. Logistic regression analysis was used to identify covariates among the baseline patient variables that were imbalanced between the 2 groups from which the model was derived. Variables included age, gender, procedure type, history of coronary artery stent, diabetes, coronary artery disease, procedure type, and smoking history. Resulting matched patients were analyzed for differences in selected intraoperative and postoperative outcomes: operating time, estimated blood loss, hospital length of stay, and 30-day operative morbidity and mortality. Statistical models were analyzed using SAS (SAS Institute, Inc, Cary, NC). The $\chi^{2}$ test was used to calculate the probability value for the comparison of dichotomous variables. Fisher's exact test (2-sided) was used when the number in any cell was less than 5 . Values are expressed as the mean \pm SD unless otherwise indicated.

\section{RESULTS}

There were 33 patients between January 2009 and April 2010 who were receiving clopidogrel at the time of general thoracic surgery. Logistic regression analysis identified having a cardiac stent, male gender, and history of cardiac dis- ease as predictors for being on a regimen of clopidogrel at the time of surgery. This process matched 132 control patients from our prospective database out of the 11,768 in it. Table 1 lists selected preoperative patient characteristics between the 2 groups. There were no significant differences between the 2 groups in age, history of coronary artery disease, presence of a coronary stent, diabetes, peripheral vascular disease, and preoperative Eastern Cooperative Oncology Group score.

The indications for clopidogrel therapy at the time of surgery were as follows: coronary artery stents in 21 patients, history of myocardial infarction and/or coronary artery bypass graft and/or valve placement in 11 patients, and severe peripheral vascular disease in 1 patient. The types of general thoracic operations performed and the intraoperative and postoperative outcomes are shown in Table 2 . The 33 patients receiving clopidogrel have been subdivided into the 14 that were receiving both clopidogrel and aspirin together at the time of surgery and the 19 patients who were receiving clopidogrel alone. These were compared with the controls. As shown, 7 of the 33 patients receiving clopidogrel had postoperative morbidity, which was atrial fibrillation in $2 \mathrm{pa}-$ tients, postoperative bleeding requiring return to the operating room in 2, and pulmonary embolism, acute myocardial infarction, and confusion in 1 each. None of the patients who underwent primary thoracotomy required a reoperation for bleeding or transfusion of blood or blood products. However, 2 of the 4 patients who underwent redo thoracotomy had significant bleeding and both required transfusion of packed red blood cells (4 and 5 units, respectively) and platelets. Both of these patients were receiving clopidogrel and aspirin. As shown in Figure 1, the amount of chest tube drainage was statistically significantly higher in patients receiving clopidogrel for postoperative days $1(P=.026)$ and $2(P=.039)$ but not for postoperative day 3 .

Table 3 provides a subanalysis of the patients who had a coronary artery stent. It shows that there were 8 patients in the clopidogrel group who had a lobectomy performed and had a coronary artery stent, and none had a perioperative myocardial infarction. This compares with the 14 control patients who had a lobectomy performed and had a coronary artery stent with 5 having a perioperative myocardial infarction and 2 dying $(P=.05)$. There was 1 operative death in the clopidogrel group. This patient underwent an Ivor Lewis esophagogastrectomy and had a postoperative myocardial infarction. There were 3 postoperative deaths in the control group. All 3 of these patients underwent lobectomy; 2 patients had a myocardial infarction and 1 had pulmonary emboli.

Table 4 details the patients who had major morbidity or mortality. There were no statistically significant differences between the outcomes for the 33 patients receiving clopidogrel compared with the controls for operative time, hospital length of stay, estimated blood loss, or morbidity when stratified by procedure. 
TABLE 1. Patient characteristics

\begin{tabular}{|c|c|c|}
\hline & $\begin{array}{c}\text { Patients } \\
\text { receiving } \\
\text { clopidogrel } \\
(\mathbf{n}=\mathbf{3 3}) \\
\end{array}$ & $\begin{array}{l}\text { Matched patients } \\
\text { not receiving } \\
\text { clopidogrel } \\
(\mathbf{n}=\mathbf{1 3 2}) \\
\end{array}$ \\
\hline Age, y (mean) $\pm \mathrm{SD}$ (range) & $67.5 \pm 9.7(36-88)$ & $66.8 \pm 9.2(49-80)$ \\
\hline \multicolumn{3}{|l|}{ Gender } \\
\hline Male & $28(87 \%)$ & $96(73 \%)$ \\
\hline Female & $5(13 \%)$ & $36(27 \%)$ \\
\hline Current cigarette smoker & $15(45 \%)$ & $58(44 \%)$ \\
\hline $\begin{array}{l}\text { History of coronary artery } \\
\text { disease }\end{array}$ & $33(100 \%)$ & $132(100 \%)$ \\
\hline History of diabetes mellitus & $7(21 \%)$ & $20(15 \%)$ \\
\hline $\begin{array}{l}\text { History of peripheral vascular } \\
\text { disease }\end{array}$ & $3(9 \%)$ & $5(4 \%)$ \\
\hline Coronary stent & $21(64 \%)$ & $43(33 \%)$ \\
\hline Bare metal & 2 & 4 \\
\hline Drug eluting stent & 19 & 39 \\
\hline $\begin{array}{l}\text { Median preoperative ECOG } \\
\text { score }\end{array}$ & 1 & 1 \\
\hline Preoperative chemotherapy & $4(12 \%)$ & $14(11 \%)$ \\
\hline $\begin{array}{l}\text { Median length of time on } \\
\text { clopidogrel }\end{array}$ & $5.2 \mathrm{mo}(0.5 \mathrm{mo}-0.2 \mathrm{y})$ & Not applicable \\
\hline $\begin{array}{l}\text { Patient on another form of } \\
\text { antiplatelet therapy* }\end{array}$ & $7(23 \%)$ & $51(39 \%)$ \\
\hline
\end{tabular}

\section{DISCUSSION}

A true clinical dilemma existed for surgeons once the Food and Drug Administration convened a panel of experts in December 2006 and published guidelines that recommended
12 months of dual antiplatelet therapy for patients who underwent placement of a coronary artery drug-eluting stent. ${ }^{11}$ Patients with cancer were not able to come to resection because of the widely documented risk of stopping these medicines prematurely ${ }^{12,13}$ However, this dilemma existed only because of the assumption that surgery could not be safely performed on patients who were receiving clopidogrel and aspirin. Hence patients with non-small cell lung cancer who had poor results on their preoperative stress test and who required coronary artery stenting most commonly received a bare metal stent. This type of stent, which often compromised their coronary artery care, requires only 4 to 6 weeks of clopidogrel and aspirin therapy. Then these patients would undergo pulmonary resection 7 to 10 days after their dual antiplatelet therapy was discontinued. This treatment strategy, while the standard of care at most institutions, actually provided suboptimal care for both the patient's lung cancer (delay in treatment) and coronary artery disease (inferior stent placed). There seemed to be no optimal solution until the concept of operating on patients who continued to receive clopidogrel was discussed. Despite the paucity of literature to support the feasibility of this approach, we were aware of surgeons besides cardiac surgeons who had operated on some of these patients either urgently or unknowingly with good results.

We tested our theory with extreme caution. We started small with our first operation being a single-incision video-assisted thoracoscopic drainage of a pleural effusion. We had packed red blood cells and platelets ready in the operating room. Surprisingly, the operative field appeared no

TABLE 2. Comparison of intraoperative and postoperative outcomes

\begin{tabular}{|c|c|c|c|}
\hline & $\begin{array}{l}\text { No. of patients on clopidogrel } \\
\text { and aspirin }(n=14)\end{array}$ & $\begin{array}{l}\text { No. of patients on clopidogrel } \\
\text { alone }(n=19)\end{array}$ & $\begin{array}{l}\text { No. of patients in } \\
\text { control group }(n=132)\end{array}$ \\
\hline \multicolumn{4}{|l|}{ Initial procedure* } \\
\hline Lobectomy (open) & 1 & 10 & 45 \\
\hline Lobectomy (robotic) & 1 & 0 & 2 \\
\hline Mediastinoscopy & 2 & 2 & 16 \\
\hline Bronchoscopy & 1 & 1 & 8 \\
\hline Decortication & 0 & 1 & 3 \\
\hline Ivor Lewis esophagogastrectomy & 1 & 1 & 8 \\
\hline Chest wall resection & 0 & 2 & 8 \\
\hline Sternotomy, resection of anterior mediastinal mass & 0 & 1 & 4 \\
\hline VATS \pm wedge resection & 5 & 1 & 26 \\
\hline Wedge resection & 3 & 0 & 12 \\
\hline $\begin{array}{l}\text { No. who returned to OR for bleeding/no. who underwent } \\
\text { primary thoracotomy and returned to OR for bleeding }\end{array}$ & 0 & 0 & 0 \\
\hline $\begin{array}{l}\text { No. who returned to OR for bleeding/no. who underwent } \\
\text { a redo thoracotomy }\end{array}$ & $2 / 2$ & $0 / 4$ & $1 / 12$ \\
\hline Average hospital length of stay, $d$ (range) & $2.0(0-6)$ & $3.0(0-23)$ & $4.1(0-28)$ \\
\hline Postoperative morbidity & $4(29 \%)$ & $3(16 \%)$ & $28(21 \%)$ \\
\hline Postoperative MACE & 0 & $1(5 \%)$ & $9(7 \%)$ \\
\hline Operative mortality & 0 & $1(5 \%)$ & $5(3 \%)$ \\
\hline
\end{tabular}




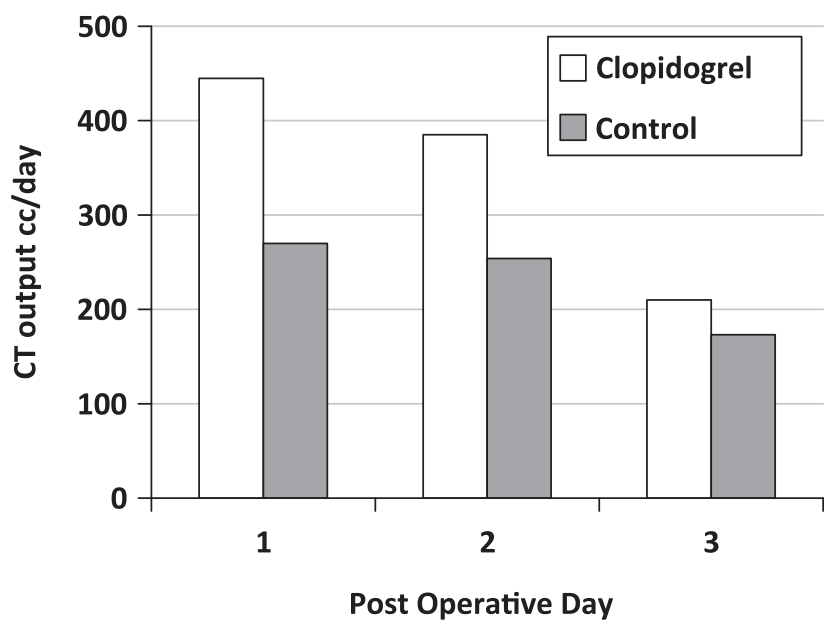

FIGURE 1. Average daily chest tube $(C T)$ output (milliliters per day) in patients who underwent lobectomy by study group. Patients receiving clopidogrel had a significantly greater chest tube output on postoperative days 1 and 2.

different from that of a patient who was not receiving clopidogrel and aspirin. We then slowly increased the degree of invasiveness of the operations by performing the following: video-assisted wedge resection for interstitial lung disease, then a thoracotomy and lymph node dissection, then a lobectomy, and finally a median sternotomy and resection of a 9$\mathrm{cm}$ thymic mass. Since then we have done 2 Ivor Lewis esophagogastrectomies, a decortication, and a robotic lobectomy. The operative field, although slightly less hemostatic in some patients, was not dramatically different and in some patients it seemed normal.

In this study we have shown that pulmonary resection (via either a thoracotomy or robotic approach) and esophagogastrectomy can be performed safely in patients who are receiving both clopidogrel and aspirin. However, two caveats should be noted. First, there appears to be a greater risk of bleeding in patients who were receiving both clopidogrel and aspirin and underwent a redo thoracotomy. This bleeding was clinically significant. Thus now we recommend that patients stop their aspirin and continue their clopidogrel alone. Second, there was a statistically significantly increased drainage in the clopidogrel group on postoperative days 1 and 2. However, since we used less than $460 \mathrm{~mL}$ per day as our criterion for chest tube removal, there was no difference in duration of chest tube placement between the 2 groups in our practice. ${ }^{14}$ Thus even for those surgeons who use a more standard definition of less than $250 \mathrm{~mL}$ per day before removal of chest tubes, there would be no difference in chest tube duration or hospital length of stay in patients who are receiving clopidogrel. Third, there may be reduction of the incidence of perioperative myocardial infarction (as suggested by other literature with much larger numbers of patients) of continuing the clopidogrel in patients with coronary artery stents.
TABLE 3. Comparisons of intraoperative and postoperative outcomes for patients with coronary artery stents

\begin{tabular}{lcc}
\hline & $\begin{array}{c}\text { Patients taking } \\
\text { clopidogrel who had } \\
\text { a coronary artery } \\
\text { stent }(\mathbf{n}=\mathbf{2 1})\end{array}$ & $\begin{array}{c}\text { Control patients } \\
\text { with a coronary } \\
\text { artery stent not taking } \\
\text { clopidogrel (n= 43) }\end{array}$ \\
\hline Initial procedure & 7 & \\
Lobectomy (open) & 1 & 14 \\
Lobectomy (robotic) & 1 & 0 \\
Mediastinoscopy & 2 & 5 \\
Bronchoscopy & 0 & 4 \\
Decortication & 2 & 0 \\
Ivor Lewis & 2 & 3 \\
Chest wall resection & 0 & 1 \\
Sternotomy, resection & & 1 \\
$\quad$ of anterior & 3 & 10 \\
$\quad$ mediastinal mass & 3 & 5 \\
VATS wedge \pm wedge & 4 & $16(37 \%)$ \\
Wedge resection & 1 & $5(13 \%)$ \\
Postoperative morbidity & $0 / 8$ & $\mathrm{p}=0.05$ \\
Postoperative MACE & & $3 / 14(36 \%)$ \\
Postoperative MACE for & $1(5 \%)$ & $3 \%)$ \\
patients who & & \\
underwent lobectomy & & \\
Operative mortality & & \\
\hline$M A C E$, Major adverse cardiac event; $V A T S$, video-assisted thoracoscopic surgery.
\end{tabular}

Lung cancer remains the most common cause of cancer death and coronary artery disease is the most common cause of all deaths. With an aged population, more people will be affected by both of these clinical problems. Many hospitals have formalized centers for treatment of heart disease, which has improved patient access to percutaneous coronary interventions. The most recent estimate by the Centers for Disease Control and Prevention was that $22.3 \%$ of Americans are smokers. All of these factors together suggest a large number of patients will have coronary stents placed and may need a pulmonary resection. While the cardiologist wants to provide the optimal coronary care and the thoracic surgeon wants to provide the optimal oncologic care, our data suggest that both can be accomplished at the same time.

There are several limitations to this study. First is the small number of patients. However, inasmuch as it is an observational study, the conclusions are probably valid. Second is its uni-institutional, nonrandomized design. Third, the propensity scores rely on the ability to match from the population of potential controls. Although our database is relatively large and contains 11,000 patients, it may not be ideal.

In conclusion, we have shown that many types of general thoracic surgical procedures can be safely performed in patients who are receiving clopidogrel and aspirin. There is no increased risk of bleeding after primary thoracotomy or minimally invasive thoracic surgery. It addition, it should be continued because it may offer a protective effect against perioperative myocardial infarction, especially in those 
TABLE 4. Patients taking clopidogrel who experienced postoperative bleeding, myocardial events, or operative mortality

\begin{tabular}{lllllll}
\hline Patient & Procedure & Taking aspirin & Coronary stent & Postop morbidity & Operative mortality & Reoperation for bleeding \\
\hline 1 & Ivor Lewis & No & Yes & Pulmonary embolism & Yes & No \\
2 & Lobectomy & Yes & Yes & Postop bleeding & No & Yes \\
3 & Wedge & Yes & No & Postop bleeding & No & Yes \\
4 & Ivor Lewis & Yes & Yes & Myocardial infarction & No & No \\
\hline
\end{tabular}

who have a coronary artery stent as their indication for antiplatelet therapy. However, in those patients who are to undergo a redo thoracotomy and who receive both clopidogrel and aspirin, there is an increased risk of bleeding secondary to the takedown of adhesions. It may be best in these patients to stop their aspirin and have them continue their clopidogrel alone. Further studies are needed.

\section{References}

1. Weitz HI, Hirsh J, Samama MM. New antithrombotic drugs. Chest. 2008;133: 234S-56S.

2. Iakovou I, Schmidt T, Bonizzoni E, Sangiorgi GM, Stankovic G, et al. Incidence, predictors, and outcome of thrombosis after successful implantation of drugeluting stents. JAMA. 2005;293:2126-30.

3. Spertus JA, Kettelkamp R, Vance C, Decker C, Jones PG, Rumsfeld JS, et al. Prevalence, predictors, and outcomes of premature discontinuation of thienopyridine therapy after drug-eluting stent placement: results from the PREMIER registry. Circulation. 2006;113:2803-9.

4. Eisenstein EL, Anstrom KJ, Kong DF, Shaw LK, Tuttle RH, Mark DB, et al. Clopidogrel use and long-term clinical outcomes after drug-eluting stent implantation. JAMA. 2007;297:159-68.

5. Newsome LT, Weller RS, Gerancher JC, Kutcher MA, Royster RL. Coronary artery stents. II: Perioperative considerations and management. Anesth Analg. 2008; 107:570-90.

6. Grines CL, Bonow RO, Casey DE Jr, Gardner TJ, Lockhart PB, Moliterno DJ, et al. American Heart Association; American College of Cardiology; Society for Cardiovascular Angiography and Interventions; American College of Surgeons; American Dental Association; American College of Physicians. Prevention of premature discontinuation of dual antiplatelet therapy in patients with coronary artery stents: a science advisory from the American Heart Association, American College of Cardiology, Society for Cardiovascular Angiography and Interventions, American College of Surgeons, and American Dental Association, with representation from the American College of Physicians. Circulation. 2007; 115:813-8.

7. Kim DH, Daskalakis C, Silvestry SC, Sheth MP, Lee AN, Adams S, et al. Aspirin and clopidogrel use in the early postoperative period following on-pump and off-pump coronary artery bypass grafting. J Thorac Cardiovasc Surg. 2009;138:1377-84.

8. Chen L, Bracey AW, Radovancevic R, Cooper JR, Collard CD, Vaughn WK, et al. Clopidogrel and bleeding in patients undergoing elective coronary artery bypass grafting. J Thorac Cardiovasc Surg. 2004;128:425-31.

9. Alpert JS, Thygesen K, Antman E, Bassand JP. Myocardial infarction redefineda consensus document of the Joint European Society of Cardiology/American College of Cardiology Committee for the redefinition of myocardial infarction. J Am Coll Cardiol. 2000;36:959-69.

10. Joffe MM, Rosenbaum PR. Invited commentary: propensity scores. Am J Epidemiol. 1999;150:327-33.

11. US Food and Drug Administration. Circulatory System Devices Panel. Available at: www.fda.gov/ohrms/dockets/ac/cdrh06.html\#circulatory. Accessed March 19, 2007.

12. Kaluza GL, Joseph J, Lee JR, Raizner ME, Raizner AE. Catastrophic outcomes of noncardiac surgery soon after coronary stenting. J Am Coll Cardiol. 2000;35: 1288-94.

13. Sharma AK, Ajani AE, Jamwi SM, Maniar P, Lakhani SV, Waksman R, et al. Major noncardiac surgery following coronary stenting: when is it safe to operate? Catheter Cardiovasc Interv. 2004;63:141-5.

14. Cerfolio RJ, Bryant AS. Results of a prospective algorithm to remove chest tubes after pulmonary resection with high output. J Thorac Cardiovasc Surg. 2008;135:269-73.

\section{Discussion}

Dr David Park Mason (Cleveland, Ohio). I have no disclosures. Dr Cerfolio, I enjoyed the talk and I enjoyed your paper very much.

I do not think that it can be overstated that clopidogrel is a potent inhibitor of coagulation, but also that you had excellent results, I think, because you did excellent surgery and cautious surgery, and not everyone is you. We have to think a little bit about the generalizability of the results. Careful and cautious surgery is obviously what you did, and the results are outstanding.

More and more patients are on a clopidogrel regimen, and many for different reasons, when they are referred to us. Twenty-one of your 33 patients were on it for coronary stents, and I think these are the ones we worry about most. The others were on it for a smattering of other reasons, such as peripheral vascular disease, for which we do not worry as much. My question is, should we treat all clopidogrel-treated patients the same? Are there some patients in whom it would not be so worrisome to consider stopping clopidogrel?

Dr Cerfolio. I think if you have a patient who has been prescribed clopidogrel because he had a clot in his toenail in 1972, which we see all the time, and there is no reason why he is on it and it's a redo, I would take the patient off and decrease my risk, However, if the patient is on it for a good reason, such as a recently deployed stent with significant coronary artery disease, especially a drug-eluting stent, I would keep him on it but stop the aspirin if the operation was a redo. If it was a primary thoracotomy, I would continue both.

Dr Mason. My second question has to do with the heterogeneity of your population. You did many different cases, and for that reason you actually gained a lot of experience in operating on these patients who were receiving clopidogrel. You mentioned that the only operations you would hesitate to perform in the future are the redo thoracotomies. Are there any other operations that you would say, I do not think that's a good idea. I saw this. I learned something from this that I would recommend to my surgeons in the future.

Dr Cerfolio. That is a great question. I would counter your first part by saying that if I can do it, everybody in this room can do it, because I am probably not going as slowly as I should. In doing the redo, the surgeon really has to slow down and take those adhesions down quickly. You cannot put your hand in there and tear stuff. You have to use the Bovie device. But I think mediastinoscopy was what I worried about the most. I had to use Surgicel hemostats (Ethicon, Inc, Somerville, NJ) on a couple of those patients. They did not bleed or need transfusions, but I think you need to be very careful with that. If you are going to do a mediastinoscopy, just make sure that the patient needs to be on the clopidogrel regimen. I do still think it is safe.

Dr Sandro Mattioli (Bologna, Italy). That is an interesting issue. In Italy we have launched a multicenter study with 7 very 
busy catheterization laboratories and 18 thoracic surgery units to afford this only on an observational basis. The point is that we do not know how frequent this problem is. I do not understand your recruitment. Did you get your patients with and without double medical therapy in sequence or were they historical cases? So the first question is frequency, because if this is frequent, we can talk to the cardiologists; otherwise, they will ignore us.

Dr Cerfolio. This is a consecutive series. Once we said we were going to follow this program, we applied it to everyone who was referred to us. By contrast, in the patients whom we treated earlier, I was stopping clopidogrel because I did not think I could operate on them while they were receiving it.

Dr Joseph B. Shrager (Stanford, Calif). Rob, the data are not very granular. It is back to the operating room or not back to the operating room or transfusion or no transfusion. Do you have no chest tube output data? Maybe if you got a little more granular you would see differences.

Dr Cerfolio. Yes, we do. That information is in the paper. However, these patients bled significantly intraoperatively and postoperatively. One patient lost $1000 \mathrm{~mL}$ and I think the other lost $1400 \mathrm{~mL}$.

Dr David J. Sugarbaker (Boston, Mass). Given the degree of equipoise as to whether or not you should leave them on their clopidogrel and operate or take them off their clopidogrel and run the risk of having a coronary event, did you consider a prospective randomized trial following an IRB approach?

Dr Cerfolio. No, because I wanted to show safety first. This would be the benchmark to go to that trial.

Dr Sugarbaker. I see. It does not seem like it would have enough power to draw any conclusions regarding safety, but I will defer to the statisticians.

Dr Bryan F. Meyers (St Louis, Mo). I think this is a useful and practical study and I thank you for doing it.

If you look at retrospective case series, when people had stopped the clopidogrel in patients with stents and operated on them, what you learn is that there is a $10 \%$ myocardial infarction rate, and among those that have an infarction, there is about a $50 \%$ death rate. This is a substantial problem in that group of patients. I would like to point out an interesting thing that came out talking to our cardiologists. The reason that the 6-month number exists-when they talk about using clopidogrel for 6 months-is that in some of the early stent trials, the company that makes clopidogrel offered 6 months of free clopidogrel. The end point of that time is not evidence-based at all, so you might as well just keep continuing it. Did you limit this to just patients who had had stents within 6 months?

Dr Cerfolio. No, we did a consecutive series of patients who came to us on a clopidogrel rgimen and operated on them.

Dr Meyers. You operated on anybody on clopidogrel regardless of how long it was before their cardiac intervention?

Dr Cerfolio. Yes, sir.

Dr Meyers. That's good.

Dr Scott I. Reznik (Temple, Tex). Inasmuch as the American Association of Anesthesiologists will prevent placement of an epidural with recent clopidogrel use, did you see any more respiratory embarrassment or more atelectasis or even more pain?

Dr Cerfolio. Good question. None of these patients got an epidural because I certainly did not want to have that conversation.
They all got an on-Q pain pump, and we did not notice the difference, but, again, it was a small number of patients.

Dr Ayman Abdul-Ghani (Anniston, Ala). I enjoyed your talk, Dr Cerfolio.

Back when I used to do cardiac surgery in Liverpool, I tried to do a study on taking down the mammary while the patient was receiving clopidogrel. We had to stop it after 10 or 15 cases, not because of take-back for bleeding but because of chest tube output. We used to transfuse that amount back into the patient. Have you considered putting the patients on a regimen of enoxaparin sodium (Lovenox)? I have done it on 1 or 2 patients, stopping the clopidogrel, using enoxaparin sodium at home, with the approval of the cardiologist, stopping it before surgery, and starting clopidogrel immediately after surgery.

Dr Cerfolio. That is one of the compromises that we were doing in the past, but it is still a compromise. The anesthesia and cardiology data are very clear. If you stop that clopidogrel, you are risking a lawsuit with much higher risk of perioperative myocardial infarction. So I do not think that is the solution. That is not going to make people happy. And the cost of enoxaparin sodium at home is through the roof. You could do that, but I do not think that is a good solution.

Dr Daniel C. Wiener (Boston, Mass). There is some literature indicating that about $20 \%$ of patients are nonresponders to clopidogrel. I wonder whether, in that small number, some of the results are skewed by the fact that some of those patients may actually be nonresponders, and how can that be addressed?

Dr Cerfolio. That is a great question and one that we cannot answer. Some of these patients did not seem to bleed any more than patients who were not receiving clopidogrel. That may be right, but I cannot answer that.

Dr Gunda Leschber (Berlin, Germany). I think you mentioned that you did a decortication as well on clopidogrel. Could you comment on this?

Dr Cerfolio. Yes. That really was risky. That was done on a patient in the hospital whom we took and did that the next day. We did okay, but we were doing a pleurectomy, a visceral pleurectomy, and I usually do a parietal pleurectomy. We went slowly and we were smart and did okay.

Dr Shrager. You had IRB approval to do this?

Dr Cerfolio. We had to inform the IRB just that we were going to try this to start.

Dr Shrager. You had IRB approval?

Dr Cerfolio. Yes. We just told the IRB we were going to do this. Dr Shrager. Did they say you were exempted from whatever?

Dr Cerfolio. No, no. They did not say we had to do anything fancy. They did not say that we needed to go through committees or boards. We went to anesthesia, went to cardiology, told the IRB we were going to try to operate on clopidogrel, and we got it in as just the safety trial.

Dr Sugarbaker. So you did not have to do an informed consent?

Dr Cerfolio. Yes, we had to do an informed consent, but we did an expedited thing. We did not need to go through the typical IRB that takes us forever.

Dr Shekar Reddy (Durham, NC). It was rather surprising to hear that your patients did not bleed at all, and that ties in with the previous question about the nonresponders. In your future work, if you add a thromboelastogram to these patients as 
a preoperative control, you will have much more robust and reliable data to prove that they have been on antiplatelets and the extent to which those drugs have been useful. If you can tie that in with your outputs, I think you will have a much more robust experimental design in the future.
Dr Cerfolio. As a scientist that is good, but as a clinician, if the patients do not bleed, I am thrilled. I do not care why they are not bleeding; they ain't bleeding. For me, the idea that all 33 were not responders is unlikely. I take your comment, but I want you to listen to my response.

Access to The Journal of Thoracic and Cardiovascular Surgery Online is reserved for print subscribers!

Full-text access to The Journal of Thoracic and Cardiovascular Surgery Online is available for all print subscribers. To activate your individual online subscription, please visit The Journal of Thoracic and Cardiovascular Surgery Online, point your browser to http://www.mosby.com/itcvs, follow the prompts to activate your online access, and follow the instructions. To activate your account, you will need your subscriber account number, which you can find on your mailing label (note: the number of digits in your subscriber account number varies from 6 to 10 ). See the example below in which the subscriber account number has been circled:

\section{Sample mailing label}

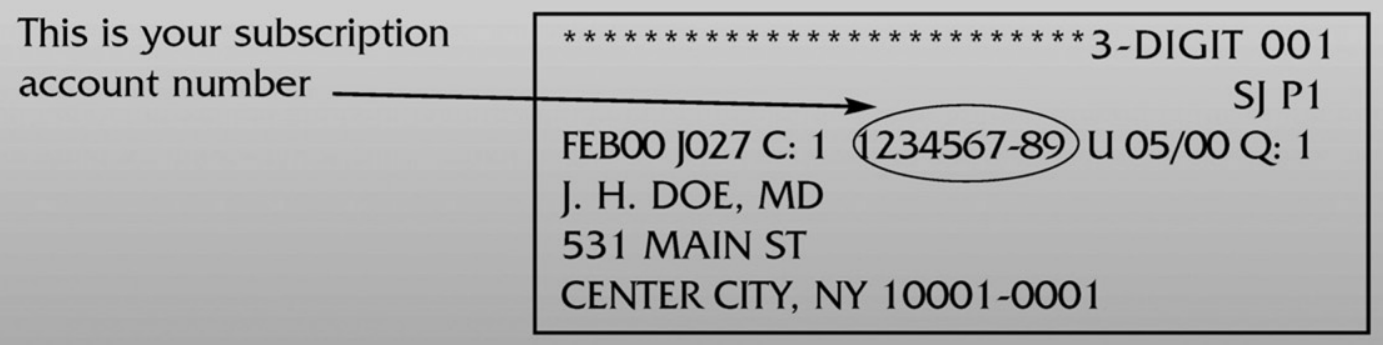

Personal subscriptions to The Journal of Thoracic and Cardiovascular Surgery Online are for individual use only and may not be transferred. Use of The Journal of Thoracic and Cardiovascular Surgery Online is subject to agreement to the terms and conditions as indicated online. 